\section{Replacement of Administration Sets Used to Administer Blood, Blood Products, or Lipid Emulsions for the Prevention of Central Line-Associated Bloodstream Infection}

To the Editor-Given our particular interest in the field of evidence-based guidelines for infection prevention, ${ }^{1-3}$ we were delighted to welcome the publication of the journal's October 2008 Supplement 1, which contained a compendium of strategies to prevent healthcare-associated infections in acute care hospitals. Indeed, in addition to supplying the healthcare worker with a very useful and excellent update of the existing recommendations, this compendium provides enlightening information regarding implementation strategies and performance measures for internal and external reporting. The paper's executive summary states that the updated recommendations are not meant to supplant the existing, more-detailed guideline documents but aim to provide practical guidance. ${ }^{4}$ Nevertheless, while reading the guidelines for the prevention of central line-associated bloodstream infections, ${ }^{5}$ some questions arose. Therefore, we gratefully take this opportunity to address these questions, which concern the management of intravenous administration sets, and we thank the authors in advance for their interest and clarification.

The article by Marschall et al. ${ }^{5}$ recommends replacement of intravenous sets not used for the administration of blood, blood products, or lipids at intervals not longer than 96 hours. Compared with the equivalent recommendation of the 2002 Centers for Disease Control and Prevention (CDC) guidelines, ${ }^{6}$ an increase in time interval from 72 to 96 hours resulted from the findings of a 2005 Cochrane systematic review, ${ }^{7}$ which has redefined the optimal timing for intravenous administration set replacement. However, the CDC guideline ${ }^{6}$ supplies additional recommendations concerning the replacement of intravenous tubing used to administer blood, blood products, or lipid emulsions within 24 hours after infusion initiation and the replacement of tubing used for propofol administration every 6 or 12 hours, whereas the current Society for Healthcare Epidemiology of America-Infectious Diseases Society of America recommendations do not provide any guidance on these subjects. We consulted the Cochrane systematic review by Gillies et al. ${ }^{7}$ and noted that, in 2005 , no evidence contradicted the existing recommendation that administration sets containing lipids be changed at least every 24 hours. Also, we did not find any additional reference to or comments on the recommended frequency for changing intravenous administration sets when administering propofol.
Therefore, we kindly ask the authors whether it is correct to conclude that the absence of recommendations $s^{5}$ concerning these issues reflects a status quo of the state of the science with regard to these preventive strategies.

\section{ACKNOWLEDGMENTS}

Financial support. S.L. holds a doctoral grant from University College Ghent.

Potential conflicts of interest. All authors report no conflicts of interest relevant to this article.

Sonia Labeau, MNSc; Dominique Vandijck, $\mathrm{PhD}$; Christelle Lizy, RN; Anne Piette, MD; Gerda Verschraegen, PhD; Dirk Vogelaers, PhD; Stijn Blot, $\mathrm{PhD}$

From the Faculty of Healthcare, University College Ghent (S.L., D. Vogelaers, S.B.), Faculty of Medicine and Health Science, Ghent University (S.L., D. Vandijck, C.L., A.P., G.V., D. Vogelaers, S.B.), Department of Microbiology (A.P., G.V.) and General Internal Medicine and Infectious Diseases (D. Vogelaers, S.B.), Ghent University Hospital, Ghent, Belgium.

Address reprint requests to Sonia Labeau, MNSc, University College Ghent, Faculty of Healthcare, Keramiekstraat 80, 9000 Ghent, Belgium (sonia .labeau@hogent.be).

Infect Control Hosp Epidemiol 2009; 30:494

(C) 2009 by The Society for Healthcare Epidemiology of America. All rights reserved. 0899-823X/2009/3005-0016\$15.00. DOI: $10.1086 / 596607$

\section{REFERENCES}

1. Labeau S, Vandijck D, Rello J, et al. Centers for Disease Control and Prevention guidelines for preventing central venous catheter-related infection: results of a knowledge test among 3,405 European intensive care nurses. Crit Care Med 2009; 37:320-323.

2. Labeau S, Vandijck D, Rello I, et al. Evidence-based guidelines for the prevention of ventilator-associated pneumonia: results of a knowledge test among European intensive care nurses. I Hosp Infect 2008; 70:180-185.

3. Blot SI, Labeau S, Vandijck DM, Van Aken P, Claes B. Evidence-based guidelines for the prevention of ventilator-associated pneumonia: results of a knowledge test among intensive care nurses. Intensive Care Med 2007; 33:1463-1467.

4. Yokoe DS, Mermel LA, Anderson DJ, et al. A compendium of strategies to prevent healthcare-associated infections in acute care hospitals. Infect Control Hosp Epidemiol 2008;29(Suppl 1):S12-S21.

5. Marschall J, Mermel LA, Classen D, et al. Strategies to prevent central line-associated bloodstream infections in acute care hospitals. Infect Control Hosp Epidemiol 2008;29(Suppl 1):S22-S30.

6. Centers for Disease Control and Prevention; O'Grady NP, Alexander M, Dellinger $\mathrm{EP}$, et al. Guidelines for the prevention of intravascular catheterrelated infections. MMWR Morb Mortal Wkly Rep 2002; 51(RR-10):1-29.

7. Gillies D, O'Riordan L, Wallen M, Morrison A, Rankin K, Nagy S. Optimal timing for intravenous administration set replacement. Cochrane Database Syst Rev 2005; 4:CD003588. 